\title{
A portable high power diode laser-based single-stage ceramic tile grout sealing system
}

\author{
J. Lawrence*, M.J.J. Schmidt*, L. Li*, R.E. Edwards** and A.W. Gale** \\ *Laser Processing Research Centre, Manufacturing Division, Department of Mechanical \\ Engineering, ** Department of Civil and Construction Engineering, University of Manchester \\ Institute of Science and Technology (UMIST), Manchester, M60 1QD, UK.
}

\section{Correspondence}

Dr. Jonathan Lawrence,

Manufacturing Engineering Division,

School of Mechanical \& Production Engineering,

Nanyang Technological University (NTU),

Nanyang Avenue,

Singapore 639798,

Tel : (44) 161 200-3806

Fax : (44) 161 200-3803

email : j.lawrence@umist.ac.uk 


\begin{abstract}
By means of a $60 \mathrm{~W}$ high power diode laser (HPDL) and a specially developed grout material the void between adjoining ceramic tiles has been successfully sealed. A single-stage process has been developed which uses a crushed ceramic tile mix to act as a tough, inexpensive bulk substrate and a glazed enamel surface to provide an impervious surface glaze. The single-stage ceramic tile grout sealing process yielded seals produced in normal atmospheric conditions that displayed no discernible cracks and porosities. The single-stage grout is simple to formulate and easy to apply. Tiles were successfully sealed with power densities as low as $200 \mathrm{~kW} / \mathrm{mm}^{2}$ and at rates of up to 600 $\mathrm{mm} / \mathrm{min}$. Bonding of the enamel to the crushed ceramic tile mix was identified as being primarily due to van der Waals forces and, on a very small scale, some of the crushed ceramic tile mix material dissolving into the glaze. In terms of mechanical, physical and chemical characteristics, the singlestage ceramic tile grout was found to be far superior to the conventional epoxy tile grout and, in many instances, matched and occasionally surpassed that of the ceramic tiles themselves. What is more, the development of a hand-held HPDL beam delivery unit and the related procedures necessary to lead to the commercialisation of the single-stage ceramic tile grout sealing process are presented. Further, an appraisal of the potential hazards associated with the use of the HPDL in an industrial environment and the solutions implemented to ensure that the system complies with the relevant safety standards are given.
\end{abstract}

Keywords: High power diode laser (HPDL); Ceramic tiles; Grout; Enamel; Glaze; Beam delivery; Safety 


\section{Introduction}

Primarily because of their superb mechanical, chemical and physical characteristics, glazed ceramic tiles command an extremely broad applications base. Ceramic tiles are typically applied to walls and floors using either tile grouts or adhesive, with tile grout (typically epoxy based) or silicon resin being used to fill the void between adjoining tiles. The most intractable problem associated with tiled surfaces is that contaminants can enter into, and exit a space via a tiled surface, through the tile grouts used to fill the void between adjoining tiles [1]. In addition, commercially available tile grouts are extremely difficult to clean and over time they consequently become contaminated and have to be removed physically or mechanically. In view of these inherent problems, however, only a moderate amount of research has been conducted in an attempt to ameliorate these attendant problems. Even fewer studies have been carried out to investigate the possibility of using lasers to provide a solution. Lawrence et al. [2-4] have exclusively pioneered the use of the high power diode laser (HPDL) to devise a two- stage ceramic tile grout sealing process. The process uses a new grout material which comprises of two distinct components: an amalgamated oxide compound grout (AOCG) substrate and a glazed enamel surface. The HPDL two-stage ceramic tile grout sealing technique was shown to yield seals that exhibited no discernible cracks or porosities. An examination of the mechanical, chemical and physical characteristics of the seals showed that the generation of the enamel surface glaze resulted in a seal with improved mechanical and chemical properties over those of conventional epoxy tile grouts.

On the other hand, much work has previously been carried to investigate the sealing of engineering ceramic surfaces using lasers. The remelting of $\mathrm{ZrO}_{2}$-based protective ceramic layers using a $\mathrm{CO}_{2}$ laser [5] was shown to result in a marked decrease the level of structural defects. Further, the $\mathrm{CO}_{2}$ laser remelting of a number of oxide ceramic coatings has been found to effect significant improvements in corrosion resistance [6], whilst the $\mathrm{CO}_{2}$ laser remelting of $\mathrm{Al}_{2} \mathrm{O}_{3}$ and $\mathrm{Al}_{2} \mathrm{O}_{3}-\mathrm{TiO}_{2}$ coatings yielded an increase in hardness and wear resistance [7]. The remelting of $\mathrm{ZrO}_{2}$-based protective ceramic layers plasma sprayed onto a variety of bond coats using continuous wave $(\mathrm{CW})$ and pulsed $\mathrm{CO}_{2}$ lasers $[8,9]$ revealed that the pulsed laser produced less cracking. The laser melting of plasma sprayed ceramic coatings based on $\mathrm{Al}_{2} \mathrm{O}_{3}, \mathrm{TiO}_{2}$ and $\mathrm{ZrO}_{2}$ using $\mathrm{CW}$ and pulsed $\mathrm{CO}_{2}$ lasers [10] revealed that the extent of cracking was a function of the total energy input to the surface and the thermophysical properties of the ceramic coatings. It was therefore concluded that to avoid cracking in such materials when remelting using the $\mathrm{CO}_{2}$ laser, it was essential to pre-heat the workpieces to around $800^{\circ} \mathrm{C}$ and thereby reduce the thermal gradient [10]. Similarly, the $\mathrm{CO}_{2}$ laser treatment of $\mathrm{Al}_{2} \mathrm{O}_{3} \mathrm{ZrO}_{2}$ and $\mathrm{TiC}$ [11-13] cladded layers on a variety of alloys has been shown to be a viable technique. What is more, Bourban et al. [14] found that the quality of $\mathrm{CO}_{2}$ laser treated $\mathrm{Al}_{2} \mathrm{O}_{3}-\mathrm{ZrO}_{2}$ cladded layers on mild steel was highly dependant on the thickness of the clad layer itself. The 
surface modification ceramics with other industrial lasers besides the $\mathrm{CO}_{2}$ laser has proved successful. After excimer laser treatment of the surface of $\mathrm{Al}_{2} \mathrm{O}_{3}$, Cappelli et al. [15] noted changes in the surface chemistry and morphology of the material, whilst Wu et al. [16] found that excimer laser treatment of $\mathrm{Al}_{2} \mathrm{O}_{3}-\mathrm{SiC}$ occasioned surface smoothing and an increase in the toughness of the material. The surface glazing of mullite with a HPDL by Schmidt and Li [17] resulted in a glaze that exhibited good adherence to the bulk ceramic but was severely cracked. The firing of vitreous enamel frits onto steel substrates using $\mathrm{CW} \mathrm{CO}_{2}$ laser irradiation has proved successful $[18,19]$. In both studies, however, pre-heating in a furnace of the steel substrate to $200^{\circ} \mathrm{C}$ was necessary in order to avoid microcracking. The firing of vitreous enamel frits onto glass substrates using $\mathrm{CO}_{2}$ lasers has also been studied [20]. Owing to the localised heating nature of laser radiation, temperatures in excess of $1000^{\circ} \mathrm{C}$ could be achieved without causing any deformation of the substrate glass. As such, it proved possible to fire $\mathrm{PbO}$-free enamel frits [21]. Moreover, the gloss and the smoothness of the laser fired enamel were comparable to those of conventional furnace fired enamels. However, in both studies, pre- and post-heating of the enamels in a furnace to temperatures in the range of the enamel melting temperature was necessary in order to relieve thermal stresses.

This paper presents a new technique whereby ceramic tiles are sealed together using a HPDL without the need for pre-heating or special atmospheric conditions. The seals generated between adjoining vitrified ceramic tiles described in this paper were found to be tough and inexpensive, as well as providing an amorphous, crack-free surface glaze. In this way the tiles were sealed together permanently, preventing any further contamination activity. Because such a seal would be an integral a part of the surface as the tiles themselves, the requirement to remove old or contaminated grout from the void between the tiles would be eliminated. In addition, this paper reports on the development of a hand-held HPDL beam delivery unit and the related procedures necessary to lead to the commercialisation of the single-stage ceramic tile grout sealing process. Along with this are included an appraisal of the potential hazards associated with the use of the HPDL in an industrial environment and the solutions implemented to ensure that the system complies with the relevant safety standards.

\section{Single-stage tile grout material development}

Commercially available epoxy tile grout is currently formulated from four main components: acrylic emulsion; limestone; dolomite and a cellulose substance. The limestone and dolomite act as fillers and the cellulose substance is added basically to thicken the grout. It is well established that glazing can only be achieved using materials containing at least some of the essential glass network forming compounds such as $\mathrm{SiO}_{2}$ and $\mathrm{BO}_{3}$, along with some glass network modifying and intermediate compounds such as $\mathrm{Na}_{2} \mathrm{O}, \mathrm{Al}_{2} \mathrm{O}$ and $\mathrm{MgO}$ [22]. As such, it proved impossible to directly glaze epoxy 
tile grouts. Also, the coating of epoxy tile grout with a vitrifiable substance was not possible since the actual bonding mechanism by which the grout adheres to surfaces to which it is applied is mechanical, or more precisely hydraulic, and is achieved as a result of the acrylic emulsion hydraulically bonding to the surface [23]. Since the grout does not bond to surfaces chemically, it is unable to withstand elevated temperatures. Indeed, at temperatures above $200^{\circ} \mathrm{C}$ the grout will actually de-bond from the surface it is applied to [24], a temperature well below the softening point of commercial vitreous coating materials.

Based on the findings of previous work conducted by Lawrence et al. [2, 4], nine different oxide compounds and three types of enamel frit were chosen as the materials with which to develop the single-stage seal. The selected oxide compounds were: pozzolana; chamotte; $\mathrm{Al}_{2} \mathrm{O}_{3} ; \mathrm{SiO}_{2} ; \mathrm{Fe}_{2} \mathrm{O}_{3}$; $\mathrm{FeS}_{2} ; \mathrm{Zn} ; \mathrm{MgO}$ and $\mathrm{ZrO}_{2}$. The selected oxide compounds were obtained in powder form with various particle sizes. To ensure particle size consistency the powders were in turn fine ground with a pestle and mortar and then sieved through a $45 \mu \mathrm{m}$ mesh. The enamel frits are commercially available and were obtained from Ferro Group (UK) Ltd. The compositions of the enamel frits consisted mainly of the following: $\mathrm{SiO}_{2} ; \mathrm{B}_{2} \mathrm{O}_{3} ; \mathrm{Na}_{2} \mathrm{O}$; Mn and small quantities of $\mathrm{Ba} ; \mathrm{Al}_{2} \mathrm{O}_{3}$ and $\mathrm{Ni}$, whilst the powder size was approximately $20 \mu \mathrm{m}$. The selected compounds and the selected enamel frits were then thoroughly mixed together in various compositions to ensure homogeneity, along with approximately $50 \%$ diluted sodium-silicate-solution so as to form a manageable paste. The single-stage grout mixtures in this paste form were then immediately applied to ordinary Portland cement (OPC) substrates $\left(50 \times 50 \times 10 \mathrm{~mm}^{3}\right)$ and, according to the findings of cursory trials conducted to determine the optimum settling time, allowed to cure for $24 \mathrm{~h}$ prior to the HPDL treatment. The thickness of the materials on the OPC substrate was monitored and kept at approximately $3 \mathrm{~mm}$ across the whole of the surface. Unfortunately it proved impossible to generate satisfactory glazes using any of these mixes; microcracking and porosity generation to varying degrees, as well as inconsistent glazing were ever present features (see Discussion). Consequently a new approach was adopted. Whereas previously the compounds and the enamel frit were combined together to form a single amalgamated mixture, the new approach specifically kept the compounds and the enamel frit apart. However, previous work by Lawrence et al. $[2-4,25,26]$ revealed that in order for the enamel frit to wet and bond to the compound mixtures, HPDL surface treatment of the compound mixtures was necessary (so as to generate a vitrified surface) prior to the application of the enamel frit. This resulted in a twostage HPDL sealing process. The solution found for this problem was to use crushed vitrified ceramic tiles as a bulk filler, since the enamel frit will readily wet this material without the need for prior HPDL surface treatment, with the enamel frit placed directly on top as shown in Fig. 1. In this way a single-stage HPDL sealing process could be achieved as theoretically the materials could be applied in a single action and only one pass of the HPDL would be required. 


\section{Experimental procedures}

\subsection{Materials preparation and application}

UK standard $150 \times 150 \times 5 \mathrm{~mm}^{3}$ vitrified ceramic tiles were cut into smaller pieces, $20 \times 20 \mathrm{~mm}^{2}$, for experimental purposes and applied in pairs to an OPC substrate using standard epoxy tile grout (Vallance Ltd). The spacing between the vitrified edges of each tile pair was the industry recommended $1.5 \mathrm{~mm}$. The fixed ceramic tile pieces were then allowed to set for the standard setting time of $24 \mathrm{~h}$. Vitrified ceramic tiles were crushed and fine ground using a pestle and mortar and then sieved to ensure a particle size of less than $30 \mu \mathrm{m}$. So as to form a manageable paste, the vitrified ceramic tile powder was mixed with approximately $50 \mathrm{wt} \%$ water diluted sodium silicate solution. The vitrified ceramic tile paste was then placed into the void, flush to the surface of the tiles and allowed to cure for $8 \mathrm{~h}$. The set mixture was then overlaid directly with a thin layer $(500 \mu \mathrm{m})$ of enamel frit which, in order to form a manageable paste, was mixed with $20 \mathrm{wt} \%$ white spirit. The composition of the enamel consisted mainly of the following: $\mathrm{SiO}_{2} ; \mathrm{B}_{2} \mathrm{O}_{3} ; \mathrm{Na}_{2} \mathrm{O} ; \mathrm{Mn}$ and small quantities of $\mathrm{Ba} ; \mathrm{Al}_{2} \mathrm{O}_{3}$ and $\mathrm{Ni}$, whilst the powder size was less than $25 \mu \mathrm{m}$. The enamel frit paste was allowed to cure for $1 \mathrm{~h}$ and then irradiated immediately with the defocused HPDL beam.

\subsection{Laser processing arrangement}

The laser used in the study was a surgical HPDL (Diomed Ltd.), emitting at $810 \mathrm{~nm} \pm 20 \mathrm{~nm}$ and operating in the $\mathrm{CW}$ mode with rated optical powers ranging from 0-60 W. The HPDL beam was delivered to the work area by means of a $4 \mathrm{~m}$ long, $600 \mu \mathrm{m}$ core diameter optical fibre, the end of which was connected to a 2:1 focusing lens assembly mounted on the z-axis of a 3-axis CNC gantry table. The single-stage ceramic tile grout was irradiated using the defocused high order mode HPDL beam with a beam spot diameter of $1.75 \mathrm{~mm}$ and HPDL powers (measured at the workpiece after fibre and optics losses using a Power Wizard power meter) of 10-45 W. Fig. 1 illustrates the laser processing experimental arrangement, wherein the defocused HPDL beam was fired along the vitrifiable enamel frit placed in the void between adjoining vitrified ceramic tiles by traversing the samples beneath the HPDL beam using the $\mathrm{x}$ - and $\mathrm{y}$-axis of the CNC gantry table at speeds ranging from $1-20 \mathrm{~mm} / \mathrm{s}$. In order to study the possible effects of different process gasses, $31 / \mathrm{min}$ of coaxially blown $\mathrm{O}_{2}$ assist gas was used to shield the HPDL optics, whilst the fumes produced were removed with an extraction system. In order to analyse the HPDL treated specimens, they were sectioned with a Struers cutting machine using a diamond rimmed cutting blade and then polished using cloths and diamond suspension pastes. The sectioned samples were then examined using optical microscopy, scanning electron microscopy (SEM), energy dispersive X-ray (EDX) and X-ray diffraction (XRD) techniques. 


\section{High power diode laser processing characteristics}

\subsection{Effect of laser operating parameters}

Ceramic tiles were successfully sealed with power densities as low as $200 \mathrm{~kW} / \mathrm{mm}^{2}$ and at rates of up to $100-600 \mathrm{~mm} / \mathrm{min}$. Within these conditions good quality surface glazes displaying neither discernible microcracks nor porosities could be generated. A typical example of a glaze generated within these laser operating parameters is shown in Fig. 2.

Variations in the laser power density were seen to have a significant effect upon the surface morphology of the enamel glazes. A minimum power density level of around $100 \mathrm{~kW} / \mathrm{mm}^{2}$ was observed, below which incomplete glazing of the enamel occurred, regardless of the traverse speed. HPDL interaction at this level resulted in a seal which appeared only partially vitrified. At a relatively medium power density $\left(200 \mathrm{~kW} / \mathrm{mm}^{2}\right)$, however, the quality of the enamel surface glaze on the enamel was much improved. Here complete vitrification of the enamel occurred, with the surface displaying very few microcracks and no porosities. When glazing with a relatively high power density $\left(300 \mathrm{~kW} / \mathrm{mm}^{2}\right)$, the quality of the enamel surface glaze was extremely poor, displaying many large microcracks and porosities.

As with power density variations, changes to the traverse speed had a significant effect upon the surface morphology of the enamel glaze. From the experiments it was observed that at relatively low $(<120 \mathrm{~mm} / \mathrm{min})$ and high $(>480 \mathrm{~mm} / \mathrm{min})$ traverse speeds, the surface condition of the enamel glazes were unacceptable. In such instances the glazed surfaces displayed many large porosities and microcracks. At medium traverse speeds in the range of $180-420 \mathrm{~mm} / \mathrm{min}$, however, good quality surface glazes on the enamel could be generated which displayed neither porosities nor microcracks.

\subsection{Glazing/melting characteristics}

Exposure of the crushed ceramic tile mix to rapid heating as a result of HPDL vitrification of the enamel frit results in further densification of the upper section of the crushed ceramic tile mix. This essentially entails the removal of the pores between the starting particles of the mix, combined with growth together and strong bonding between adjacent particles [27]. As the microscopic crosssectional examination of the single-stage seal shown in Fig. 3 reveals, the crushed ceramic tile mix exhibits an upper densified layer, with a gradual decrease in the amount of densification as the depth increases. In addition, an XRD analysis of the crushed ceramic tile mix after HPDL vitrification of the enamel frit revealed that the structure was mainly polycrystalline in nature, with only partial vitrification taking place. This indicates that the densification of the upper sections of the crushed ceramic tile mix is achieved primarily by solid-state material transport, driven by differences in freeenergy or chemical potential [27]. However, the fact that partial vitrification of upper section of the 
crushed ceramic tile mix was observed suggests that the formation of a liquid glass phase was induced, which is often the case with ceramic materials [27].

\subsection{Bonding characteristics}

The typical bond region between the enamel glaze and the crushed ceramic tile is shown in Fig. 4. As is evident from Fig. 4, there is no dendritic growth in bond region which is characteristic of enamels fired onto substrates containing Fe, Si and in particular, Co [28]. However, as one can see from Fig. 4 , it appears that an interface region in which some of the base crushed ceramic tile mix had dissolved into the enamel exists. Indeed, an EDX analysis of the bond region between the enamel seal and the crushed ceramic tile mix revealed that within this interface region, elements unique to both components of the single-stage ceramic tile grout seal were present.

\section{Mechanical, chemical and physical characteristics of the single-stage ceramic tile grout seal}

Existing British and international standards in relation to tile grout are concerned only with water absorption and compressive strength, whilst for actual ceramic tiles, standard tests exist for the determination of water absorption and chemical resistance. As such it was not possible to test the HPDL generated seals according to, and strictly adhering to, established tests. Consequently, wherever possible, tests based on current standards were developed to investigate specific aspects of particular relevance to the HPDL generated seals, namely the pull-off strength, the surface roughness, the rupture/impact strength, the wear resistance, the permeability characteristics (water) and the corrosion resistance. Details of these actual tests can be found elsewhere [3]

Marked variations in the results with changes in the laser operating parameters were observed. But little variation within the optimum laser operating parameters was observed, thus implying that neither the power density nor the traverse speed influenced the bond strength of the enamel glaze. The average strength of the bond between the enamel glaze and the crushed ceramic tile mix was recorded as $79 \mathrm{MPa}$, whilst the strength of the bond between the enamel glaze and the borosilicate glass surface of the ceramic tiles was found to be $52 \mathrm{MPa}$. A post-test analysis of the samples showed that in both cases, bond failure occurred at the interface between the enamel glaze and the materials. Further, an optical analysis of the detached surfaces showed that the enamel had detached cleanly and completely from the crushed ceramic tile mix and the borosilicate glass surface of the ceramic tiles.

The surface roughness of the enamel glaze is one of the most important features of the single-stage ceramic tile grout seal, for it is this that determines the cleanability of the tiled surface as a whole. Using the Taylor-Hobson Surtonic 3+ surface texture measuring instrument, a series of measurements 
were taken on the surface of a layer of an epoxy grout (polished to ensure a measurement could be taken), the vitrified surface of a ceramic tile and the surface of the enamel glaze. On each sample, four measurements were taken in different positions and in different directions on the surface, with an average being taken. Table 1 summarises the surface roughness ( $\mathrm{Ra}$ ) measurement results. As is evident from Table 1, the surface roughness of the enamel seal is many times less than that of a conventional epoxy grout, even when polished. In ordinary operating conditions where the surface roughness of the epoxy grout is not polished, but is determined by the means of application, the surface roughness was measured to be in excess of $30 \mu \mathrm{m}$. Clearly, in this situation the surface roughness, and hence the cleanability, of the single-stage ceramic tile grout seal will be considerably better.

Tests were conducted to determine the rupture strength of the enamel glaze when comprising a complete single-stage ceramic tile grout seal and the vitreous glaze on the surface of a ceramic tile. The results of the experiments revealed that there was little variation between the average rupture strength of the enamel seal and the vitreous tile glaze, $2.8 \mathrm{~J}$ and $3.0 \mathrm{~J}$, with the enamel seal ranging from 2.5-3.0 J, whilst the vitreous tile glaze ranged from only 2.9-3.0 J. It is interesting to note that because of the shape of the tile edges, the enamel glaze when HPDL fired naturally assumes a concave surface geometry. As such, the strains within the enamel layer are higher, therefore reducing the strength (if the enamel glaze assumed a flat surface profile) by some 40-50\% [29]. Additionally, it is well established that substrate thickness has a significant effect upon the rupture strength of an enamel coating [29]. As such, because the thickness of the single-stage ceramic tile grout seal as a whole was not controlled as accurately as the thickness of the bulk ceramic tile material, then slight variations in the recorded rupture strength are perhaps to be expected.

The wear resistance of a material is generally determined by the hardness of the material in comparison with the hardness of other materials with which it comes into contact [30]. Hence the greater hardness of the compositional components of the enamel glaze on the single-stage ceramic tile grout (principally $\mathrm{SiO}_{2}, \mathrm{~B}_{2} \mathrm{O}_{3}, \mathrm{Na}_{2} \mathrm{O}$ and $\mathrm{Mn}$ ) in comparison with the epoxy tile grout (principally $\mathrm{CaCO}_{3}$ and dolomite) probably results in improved wear resistance. However, wear resistance does not always increase with hardness [31]. Tests were therefore to determine the exact difference in wear resistance between the conventional epoxy tile grout and the glazed enamel surface of the single-stage ceramic tile grout. Fig. 8 shows the relationship between weight loss and the friction time for the test pieces. As one can see, the wear resistance of the glazed enamel seal is considerably greater than the epoxy tile grout, with the weight loss being 9 times lower than for the epoxy tile grout after $4 \mathrm{~h}$, and 14 times lower after $8 \mathrm{~h}$.

Perhaps the most important function of the single-stage ceramic tile grout is its propensity for preventing harmful agents from permeating through it. In order to test the permeability of the single- 
stage ceramic tile grout seal, in particular the glazed enamel surface, comparison experiments with conventional epoxy tile grout were conducted in terms of water permeability. The tests were based on BS 6906 [32]. From the tests it was found that the conventional epoxy tile grout had an average water permeability of approximately $4.18 \times 10^{-3} \mathrm{mg} / \mathrm{h} . \mathrm{cm}^{2}$, whilst the single-stage ceramic tile grout seal exhibited no measurable permeability. Such a result confirms that not only is the enamel seal fully amorphous, but that since there are no cracks or porosities in the enamel glaze or the interface between the enamel glaze and the borosilicate glass tile surface, it is reasonable to assume that a continuous impervious surface has therefore been created across the surface of the tiles and the seal.

Tiled surfaces are often subjected to corrosive substances, either as part of the normal service environment and/or as a result of routine cleaning. Consequently, corrosion resistance tests based upon BS 6431 [33] were conducted using nitric acid $\left(\mathrm{HNO}_{3}\right)$, sodium hydroxide $(\mathrm{NaOH})$ and a detergent cleaner (MP9, Premier Products). The experiments were carried out by dropping small amounts of the corrosive agents in the concentration ratios of $80 \%, 60 \%, 40 \%, 20 \%$ and $10 \%$ on to the surface of the epoxy tile grout and the glazed enamel surface of the single-stage tile grout at hourly intervals for $4 \mathrm{~h}$. The samples were then examined optically and mechanically tested in terms of compressive strength and wear. High concentrations of the various corrosive agents were used principally to accelerate the tests. However, in practice $60 \% \mathrm{HNO}_{3}$ is used within the nuclear processing industry as a solvent for nuclear fuels [34], whilst within the food processing and brewing industries, tiled surfaces are washed repeatedly many times a day with detergent cleaners [35]. All three substances in the concentrations $80 \%, 60 \%$ and $40 \%$ were seen to immediately attack the epoxy tile grout surface, with the $\mathrm{HNO}_{3}$ and $\mathrm{NaOH}$ attacking with greater severity than the detergent. In contrast, the glazed enamel displayed no discernible microstructural changes or signs of devitrification due to corrosion. Tests conducted according to ASTM C579-91 [36] revealed that exposure of the epoxy tile grout to the reagents had a significant effect upon the compressive strength and the wear resistance of the epoxy grout. Exposure of the epoxy grout to $\mathrm{HNO}_{3}$ and $\mathrm{NaOH}$ in the concentrations $40-80 \%$ resulted in an average loss of compressive strength of approximately $35-71 \%$. In the case of the detergent, a significant loss in compressive strength only occurred with concentrations above $40 \%$. Here the average loss in compressive strength for concentrations in the range $60-80 \%$ was approximately $15-30 \%$. This compares with no discernible difference in either the wear resistance or the compressive strength single-stage ceramic tile grout. Likewise, the wear resistance of the epoxy grout was significantly affected, particularly through interaction with the $\mathrm{HNO}_{3}$ and the $\mathrm{NaOH}$. Here the weight loss was approximately 5 times higher than for the unexposed epoxy tile grout after $4 \mathrm{~h}$, and approximately 10 times higher after $8 \mathrm{~h}$ for both reagents. In the case of the detergent, the weight loss was twice as high as that recorded for the unexposed epoxy tile grout after $4 \mathrm{~h}$, and 5 times higher after $8 \mathrm{~h}$. 


\section{Discussion of single-stage ceramic tile grout seal characteristics}

The failure to generate complete glazes with the initial tile grout combinations detailed previously along the full length and breadth of the HPDL interaction zone can be attributed almost entirely to the wettability and bonding characteristics of the molten optimum single-stage tile grout. The bonding of particles takes place by means of localised laser induced heating. The duration of the laser beam incident on any one particle is short, typically between 0.5 and $25 \mathrm{~ms}$. Therefore the thermallyinduced bonding reactions must be kinetically rapid. Two such mechanisms are viscous flow when the powder has the appropriate temperature dependant viscosity and melting.

Materials with strongly temperature-dependent viscosities (or low activation energy for viscous flow) have been readily processed using laser radiation. Such materials include a number of thermoplastic polymers and rubber. Even at temperatures approaching the melting point, metals and ceramics are orders of magnitude more viscous than polymeric materials. For this reason, solid-state bonding mechanisms are not applicable for laser sintering. Thus a melting/solidification approach has been developed [27]. Attempts to laser sinter a number of metals [38, 39] and ceramic materials $[2,4,26$, 27] have revealed the phenomena of 'balling'. Here, when melting has been induced by the laser beam, the molten powder consolidates rapidly into a spheres approximately equal to the laser beam diameter rather than consolidating into a continuous layer. Such an occurrence was observed after HPDL interaction with the initial single-stage tile grout mixtures. It is believed that balling of the initial single-stage tile grout compounds was caused by the material possessing a low melt viscosity which in turn allows surface energy effects to determine the final geometry. As such, since the molten material is often completely contained by loose powder rather than a fully dense material, then this powder is unable to exert tensile traction on the liquid to confine the melt to a layerwise geometry.

As mentioned previously, within the optimum operating parameters, the HPDL fired enamel glazes on the surface of the single-stage tile grout seals generally displayed neither porosities nor microcracks. The major reason for this highly beneficial occurrence is the value of the thermal gradient, $\Delta \mathrm{T}$, induced in the enamel during HPDL irradiation. This is due partly to the fact that the softening point of the enamel powder is around $500^{\circ} \mathrm{C}$, hence the tensile stresses that result from the unrelieved elastic stresses that occur due to the contraction of the material between the softening point $\left(500^{\circ} \mathrm{C}\right)$ and ambient temperature $\left(20^{\circ} \mathrm{C}\right)$ are reduced to a value well below that of the fracture strength of the enamel. The thermal stress, $\sigma$, induced by a thermal gradient can be calculated using the Kingery equation:

$$
\sigma=\frac{E \alpha \Delta T}{1-v}
$$


where, $E$ is Young's modulus, $\alpha$ is the coefficient of thermal expansion and $v$ is Poisson's ratio. $\Delta \mathrm{T}$ is the difference between the critical temperature (below which stresses can no longer be relieved) and ambient temperature. For the enamel used this is the difference between the softening point, $500^{\circ} \mathrm{C}$ and ambient temperature $20^{\circ} \mathrm{C}$. Since the softening point of the enamel is $500^{\circ} \mathrm{C}$, that is the enamel can be plastically deformed at temperatures above $500^{\circ} \mathrm{C}$, then the thermal stresses arising during cooling from above $500^{\circ} \mathrm{C}$ are relieved by plastic deformation. But unrelieved elastic stresses result due to contraction occurring between $500^{\circ} \mathrm{C}$ and ambient temperature. Thus for the enamel used $\Delta \mathrm{T}=480^{0} \mathrm{C}$. So, by using the following values for the enamel: $\mathrm{E}=6.25 \times 10^{4} \mathrm{MN} / \mathrm{m}^{2}, \alpha=33 \times 10^{-7} \mathrm{~K}^{-1}$ and $v=0.162[40]$ and introducing them into Eq. (1), the thermal stress induced in the enamel during HPDL irradiation is calculated to be $118 \mathrm{MN} / \mathrm{m}^{2}$. This value is below that of the fracture strength of the enamel, $135 \mathrm{MN} / \mathrm{m}^{2}$ [40], and as such cracking will not occur, thus rendering any pre- or postheating of the enamel completely unnecessary.

According to the types of materials used, complex combinations of the various bonding mechanisms actually come into play [41]. For the crushed ceramic tile mix and the enamel, the mechanisms involved in ceramic-glass bonding are reasonably applicable. These principally include: physical bonding (van der Waals forces), chemical bonding (oxide transformation and $\mathrm{O}_{2}$ bridging) and on a very small scale, electrochemical reactions such as the electrolytic effect (redox reaction) due to the presence of ferric oxides within the crushed ceramic tile mix reacting with other oxides in the enamel [41]. However, in the case of the crushed ceramic tile mix and the enamel, the predominant bonding mechanism results from physical forces; since adhesion between many materials is assured by electron transfer and is, therefore, related to bandgap energy [42]. Thus for non-conducting materials, such as the crushed ceramic tile mix, with large bandgaps, there will be practically no free charges inside the ceramic crystals, even at elevated temperatures. In this case the electron transfer at the interface will not take place since the electron transfer depends exclusively on the concentration of free charges in the ceramic crystal [42]. As a result, the chemical contribution to the work of adhesion is negligible [42]. Nevertheless, the bonding mechanism between the HPDL treated crushed ceramic tile mix and the enamel may not be entirely due to physical forces owing to the fact that enamel glazes on ceramic materials such as the crushed ceramic tile mix are typically bonded as a result of some of the base material dissolving into the glaze [42]. Indeed, it is well known that $\mathrm{Na}^{+}$is extremely mobile and can, therefore, diffuse to create an interfacial zone of intermediate composition. However, such an interfacial zone was not observed during a cross-sectional analysis of the bond region. 


\section{Development of the portable high power diode laser-based single-stage ceramic tile grout sealing system}

The design requirements for the single-stage ceramic tile grout sealing system can be categorised into three different groups: the process supply system; process control and the waste removal system. The process supply system encompasses the laser, the optics system, the gas supply and any chemicals that may be required. Process control includes the monitoring and control of the operation, any possible logging requirements, and the main safety circuit. The waste removal system includes the extraction system for gaseous and particulate matter. Filtration systems for these waste materials can be added as their generation from the process becomes manifest. To lend the system the ability to be portable, as well as providing the system as much commercial application flexibility as possible, a system based on a hand-held device was decided upon. This subsequently generates a number of prerequisite requirements which define the capabilities of the intended system. These are principally:

1. Process Specifications - Scanning speeds between 100 and $600 \mathrm{~mm} / \mathrm{s}$, irradiance levels of between 100 and $300 \mathrm{~kW} / \mathrm{mm}^{2}$, variable spot sizes between 1 and $5 \mathrm{~mm}$ diameter (expected to lie in the region of $1.5 \mathrm{~mm}$ ) and a flexible power delivery system, i.e. fibre optic beam delivery system.

2. Safety Requirements - A reasonable flow of process gas to shift any particulate matter generated, Class 1 laser safety standard through the incorporation of interlock systems, guards etc. and filtration and gas absorption devices to be added as required

In Fig 6 a rendered solid model of the hand-held HPDL beam delivery system is shown. The basic specification envelope is approximately $170 \times 130 \times 130 \mathrm{~mm}^{3}$. The main housing unit of the device is machined from a solid aluminium block, with the additional components such as the handle, screen, optics core, extraction piping, optical fibre units, etc. being manufactured individually and then attached around the main housing unit. The basic design of the main housing unit holds the optics core and nozzle along the central axis, with the tip of the nozzle being just above the intended interaction spot. The end of the nozzle is surrounded by a reflective dome, cut into the main block, with its centre on the interaction spot. This will ensure that any reflected radiation is returned straight back to the interaction spot, thus allowing for a more efficient process. The supply of process gas is provided through the optics core and is therefore coaxial with the laser radiation. To monitor the process and to ensure good validation of the parameters, the speed is taken on one of the interlock wheels and displayed on top of the handle. An endoscope camera in the dome allows for monitoring of the interaction zone and ensures that the operator has good control over the alignment of the beam. The lower edge of the central block is approximately $1 \mathrm{~mm}$ above the tile surface. This gap, although small, must be closed for safety reasons. 
The $1 \mathrm{~mm}$ gap corresponds to a 2 degree opening angle, seen from the centre of the dome. Assuming a lambertian body as the target material, $0.06 \%$ of the reflected radiation would escape through this gap (integrated over all directions). The gap area of the sphere can be approximated at $1.9 \mathrm{~cm}^{2}$. Assuming the laser system operates at $110 \mathrm{~W}$ output power, this will result in a leakage power of $0.066 \mathrm{~W}$, and therefore in a leakage power density of $3.5 \mathrm{~W} / \mathrm{mm}^{2}$. Although this figure is very small, for safety reasons this must be blocked also. To this end, a row of carbon brushes will be attached to the edges of the main block, in effect optically sealing the interaction area and ensuring Class 1 laser operation, in conjunction with the wheel interlocks, which interrupt the laser should the system be lifted off the processing surface.

Particulate extraction is handled by four $10 \mathrm{~mm}$ diameter extraction pipes, which are set in even gaps around the edges of the dome. Previous designs for a paint stripping processes [43], utilising three $6 \mathrm{~mm}$ pipes have proven very successful, and the additional capacity may come in useful for grout removal applications [44]. The extraction system will remove the material through the handle into a particulate filter. Gas absorption filtration can be added when necessary. Extraction and supply of gas, command signals, as well as the laser fibre will be run through an umbilical line which enters the hand-piece through the handle. This has the added advantage of allowing for a protective sleeve around all utility lines, which can be included in the interlock chain. Any damage to this unit, and potentially the fibre, will prohibit the use of the laser system. Naturally, the operation switch will be configured in "hold-to-run" mode so as to avoid accidental operation.

\section{Associated safety aspects of the high power diode laser-based single-stage ceramic tile grout sealing system}

As specified in ISO 11553 [45], it is a requirement that no human exposure to radiation exceeding levels of Class 1, according to BS EN 608251-1 [46], is possible during production (normal or otherwise). In practice, this requires that no access to a danger zone is possible during operation. Any laser system for production use will in effect have to be a Class 1 system, hence any design will have to take this issue into account. The maximum permissible exposure (MPE) is defined in BS EN 60825-1 [45] and is subject to the laser intensity, spectral distribution and temporal parameters of the radiation system, as well as the type of exposure, i.e. ocular or skin exposure. If one assumes a $10 \mathrm{~s}$ exposure time limit, then the ocular and skin exposure limits are defined as:

$$
\begin{aligned}
& \text { Ocular exposure limit }=18 \cdot t^{0.75} \cdot C_{4} C_{6}\left(\mathrm{~J} / \mathrm{m}^{2}\right) \\
& \text { Skin exposure limit }=1.1 \cdot 10^{4} \cdot t^{0.25} \cdot C_{4}\left(\mathrm{~J} / \mathrm{m}^{2}\right)
\end{aligned}
$$


where $t$ is time, $C_{4}$ is a correction factor defined as $10^{0.002 \cdot(\lambda-700)}$, which for our case (since $\lambda=810$ nm) results in $C_{4}=1.659$ and $C_{6}$ can be assumed to be 1 , even if the exposure limit should be increased for diffuse viewing. So, the resulting MPE values determined with assumed exposure times of $10 \mathrm{~s}, 1 \mathrm{~s}$ and $10^{-3} \mathrm{~s}$ are given in Table 3.

The MPE equivalent power density values are relevant for exposure times from $10^{-3} \mathrm{~s}$ to $10 \mathrm{~s}$, which it is believed cover all instances of the single-stage ceramic tile grout sealing processes. Additionally, blink reflexes, as well as pain reactions can be assumed to ensure a sufficient limitation in exposure times $[47,48]$. It can be seen that the leakage power density that would be generated from the handpiece without a lower edge beam guard is some way over the MPE irradiance for ocular exposure. It should, however, be noted that the MPE calculated in this case is a worst case scenario, assuming the unlikely occurrence of $100 \%$ reflection from the interaction zone. The value also does not account for the expanded angular effects through the diffuse radiation. That is, it assumes the exposure occurs directly at the edge of the handpiece. It can be said with a reasonable amount of confidence that the system would adequately fulfil the requirements for a Class 1 system, as long as the interlock chain ensures that there is no irradiation, if the system is not on a process surface.

\section{Conclusions}

Ordinary vitrified ceramic tiles have been successfully sealed using a $60 \mathrm{~W}$ high power diode laser (HPDL) with power densities as low as $200 \mathrm{~kW} / \mathrm{mm}^{2}$ and at rates as high as $600 \mathrm{~mm} / \mathrm{min}$. A singlestage process has been devised using a crushed ceramic tile mix and a commercially available vitreous enamel. The crushed ceramic tile mix provides a tough, inexpensive bulk substrate which simply acts a filler for the void between adjoining tiles, whilst the enamel provides an impervious surface glaze.

It is believed that the failure to generate complete glazes with the initial single-stage ceramic tile grout compounds or an amalgamation of the crushed ceramic tile mix and the enamel frit, regardless of the ratios used, can be attributed to the wettability and bonding characteristics of the materials. More specifically, because the molten material is often completely contained by loose powder rather than a fully dense material, then this powder is unable to exert tensile traction on the liquid to confine the melt to a layerwise geometry. Hence attempts to seal these initial single-stage grout mixtures with the HPDL resulted in the formation of solid spheres approximately equal in diameter to the width of the HPDL beam, a phenomena known more commonly as 'balling'. Bonding of the enamel to the crushed ceramic tile mix was identified as being mainly due to van der Waals forces (dispersion forces) and, on a very small scale, slight microstructural changes occurring at the interface between the crushed ceramic tile mix and the molten enamel resulting in some of the crushed ceramic tile mix 
material dissolving into the glaze. Optical inspection and water permeability tests revealed that a complete bond was achieved between the enamel glaze and the crushed ceramic tile mix, as well as between the enamel glaze and the vitrified surface of the ceramic tiles themselves.

The single-stage ceramic tile grout sealing process has been characterised and has in turn evolved to such an extent that the development of a hand-held HPDL beam delivery unit and the related procedures necessary to lead to the commercialisation of the process have been successfully carried out. Furthermore, an appraisal of the potential hazards associated with the use of the HPDL in an industrial environment has been conducted, with the solutions derived being implemented to ensure that the system complies with the relevant safety standards.

\section{Acknowledgements}

The authors would like to express their gratitude to the EPSRC: Process Engineering Group (Grant No. GR/M46068) for their financial support of this work. The authors are also grateful to BNFL, Diomed Ltd., Ferro Group (UK) Ltd. and Ove Arrup \& Partners for their technical assistance.

\section{References}

1. Taylor GD. Construction materials. London: Longman Scientific \& Technical, 1991.

2. Lawrence J, Li L, Spencer JT. Optics Laser Tech. 1998; 30: 205-14.

3. Lawrence J, Li L, Spencer JT. Optics Laser Tech. 1998; 30: 215-23.

4. Lawrence J. PhD Thesis, UMIST, 1999.

5. Adamski A, McPherson R. Proceedings of the $11^{\text {th }}$ International Thermal Spraying Conference, May 1986 (ASME, New York, 1986), pp. 555-564.

6. Kobylanska-Szkaradek K. Lasers in Eng. 1999; 9: 127-38.

7. Yang YZ, Zhu YL, Liu ZY, Chuang YZ. Mater. Sci. Eng. A, 2000; 291: 168-72.

8. Mordike BL, Sivakumar R. Proceedings of ECLAT '86, June 1986 (SPIE, Bellingham, WA, 1986), pp. 373-381.

9. Tsai HL, Tsai PC. J. Mater. Eng. Performance, 1998; 7: 258-64.

10. Sivakumar R, Mordike BL. J. Surf. Eng. 1998; 4: 127-40.

11. Nowotny S, Richter A, Tangermann K. J. Thermal Spray Tech. 1999; 8: 258-62.

12. Ouyang JH, Nowotny S, Richter A, Beyer E. Ceramics Int. 2001; 27: 15-24.

13. Sun RL, Yang DZ, Guo LX, Dong SL. Surf. Coatings Tech. 2001; 135: 307-12. 
14. Bourban S, Jansen F, Hofmann H, Kurz W. Zeitschrift fur Metallkunde, 1999; 90: 608-14.

15. Capelli E, Orlando S, Sciti D, Montozzi M, Pandolfi L. Appl. Surf. Sci. 2000; 154: 682-8.

16. Wu YN, Feng ZC, Liang J. J. Mater. Sci. Tech. 2000; 16: 401-4.

17. Schmidt MJJ, Li L. Appl. Surf. Sci. 2000; 168: 9-12.

18. Yu J, Wu W, Wang M. Chinese J. Lasers, 1993; B2: 377-83.

19. Wang M, Yu J. Chen J, Wu W. Proceedings of ICALEO '95, October 1995 (Laser Institute of America, Orlando, FL, 1996), pp. 699-709.

20. Buerhop C, Weissmann R. Glass Sci. Tech. 1995; 68: 147-52.

21. Hahn K, Buerhop C, Weissmann R. Glass Sci. Tech. 1996; 69: 1-6.

22. Doremus RH. Glass science. New York: John Wiley \& Sons, 1994.

23. Allyn G. Basic concepts of acrylic emulsion paint technology. Philadelphia: Rohm \& Haas Co., 1957.

24. Gomersol S. Letter to author, January 1996.

25. Lawrence J, Li L, Spencer JT. Mater. Sci. Eng. A, 1999; 266: 1067-74.

26. Lawrence J, Li L, Spencer JT. Surf. Coatings Tech. 1999; 115: 273-81.

27. Richerson DW. Modern ceramic engineering. New York: Dekker, 1992.

28. Pask, JA, Tomisa AP. in Engineered materials handbook: Ceramics and glasses, (ed. S.J. Schneider, Metals Park: ASM International 1991), pp. 482-92.

29. Vargin VV. Technology of enamels. London: MacLaren \& Sons, 1965.

30. Dickson H. Glass: A handbook for students and technicians. London: Hutchinsons Scientific and Technical Publications, 1951.

31. Petitbon A, Boquet L, Delsart D. Surf. Coat. Tech. 1991; 49: 57-61.

32. BS 6906: Part 3: 1989, Determination of water flow normal to the plane of a geotextile under a constant head.

33. BS 6431: Part 19: 1984, Ceramic wall and floor tiles: Method for determination of chemical resistance. Glazed tiles.

34. Spencer JT. Letter to author, October 1997.

35. Verran J. Letter to author, October 1997.

36. ASTM C597-91, Standard test method for compressive strength of chemical-resistant mortars, grouts, monolithic surfacings and polymer concretes.

37. Bourell DL, Marcus HL, Barlow JW, Beaman JJ, Deckard CR. US Patent \#4944817 (1991). 
38. Haase P. MSc. thesis, University of Texas at Austin, 1989.

39. Manriquez-Frayre JA, Bourell DL. Solid Freeform Fabrication Symposium, 1991, San Diego, CA., pp. 99-107.

40. Simpkins EA. Letter to author, October 1997.

41. Greenhut VA. in Engineered materials handbook: Adhesives and sealants, (ed. H.F. Brinson, Metals Park: ASM International, 1991), pp. 298-311

42. Li JG. Mater. Lett. 1992; 22: 169-74.

43. Schmidt MJJ, Li L, Spencer, JT. J. Laser Apps. 2000; 12: 134-41.

44. Lawrence, J, Li, L, Spencer, JT. Proceedings of ICALEO '96, October 1996 (Laser Institute of America, Orlando, FL, 1997), pp. 105-114.

45. ISO 11553:1996, Safety of machinery - Laser processing machines.

46. BS EN 608251-1: Part 1: 1994, Safety of laser products. Equipment classification, requirements and users guide.

47. Schreiber P, Dahmen M, Alunovic M, Kreutz E. J. Laser Appl. 1998; 10: 181-5.

48. Alunovic M, Backes G, Kreutz E, Scheller D, Schreiber P. Laser Praxis, 1996; 32: 96-104. 


\section{List of Figs.}

Fig. 1. Schematic illustration of the experimental set-up for the HPDL single-stage ceramic tile grout sealing process.

Fig. 2. Typical optical surface view of the glazed enamel surface of the single-stage ceramic tile grout $\left(200 \mathrm{~kW} / \mathrm{mm}^{2}\right.$ and $\left.240 \mathrm{~mm} / \mathrm{min}\right)$.

Fig. 3. Typical cross-sectional SEM view of the upper densified layer on the crushed ceramic tile mix.

Fig. 4. Typical cross-sectional SEM view of the bond region between the enamel glaze and the crushed ceramic tile mix.

Fig. 5. Relationship between weight loss and friction time for the untreated and HPDL generated glaze on the OPC surface of concrete.

Fig. 6. Solid rendered view of the hand-held HPDL-based single-stage ceramic tile grout sealing system. 
Fig. 1

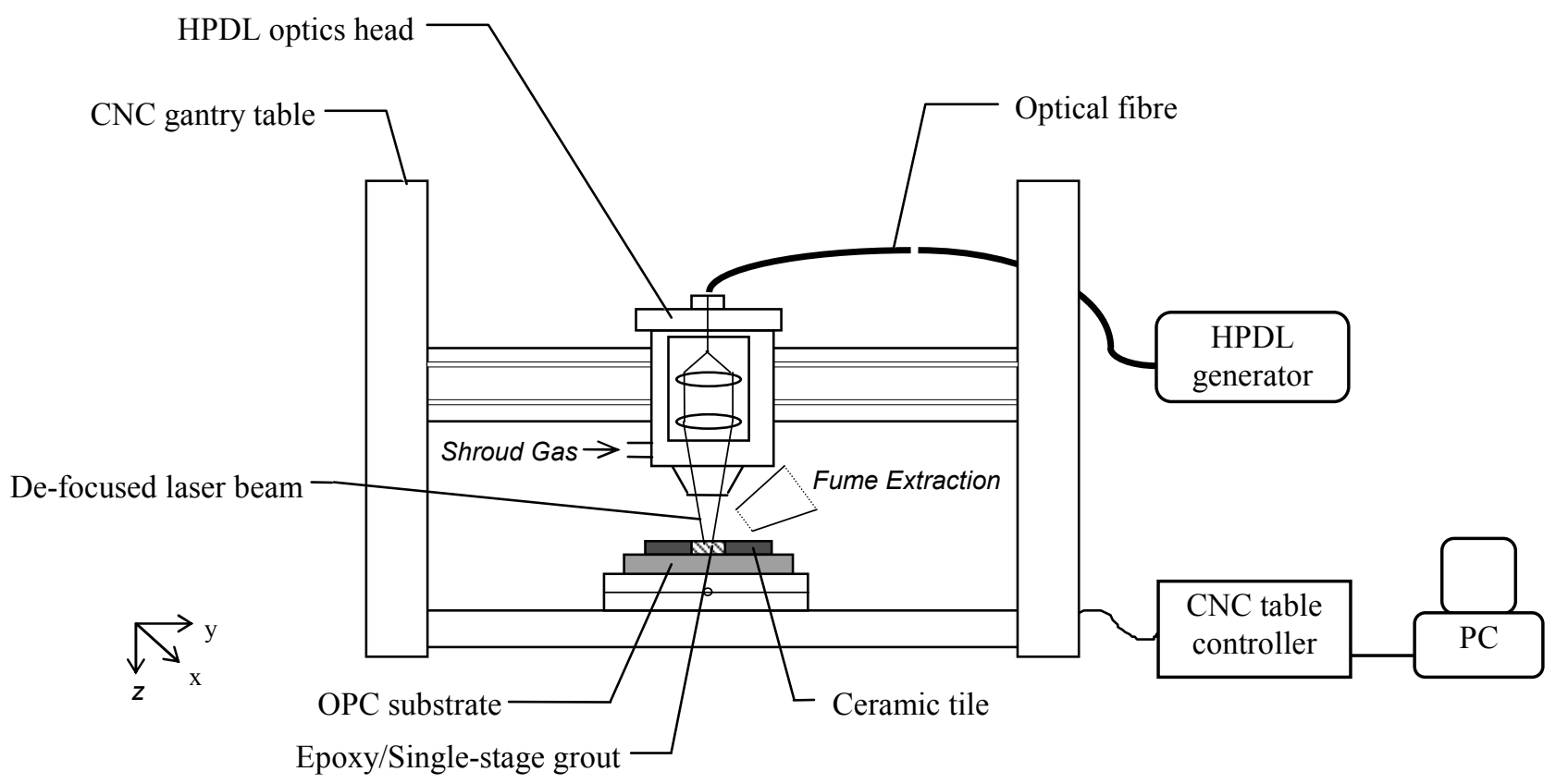


Fig. 2

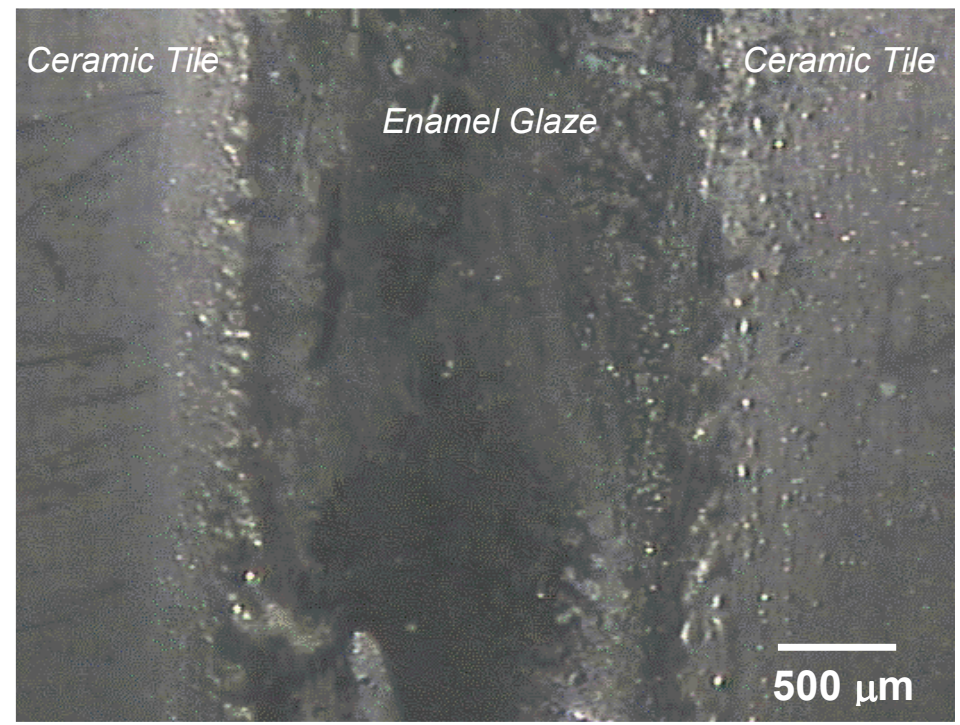


Fig. 3

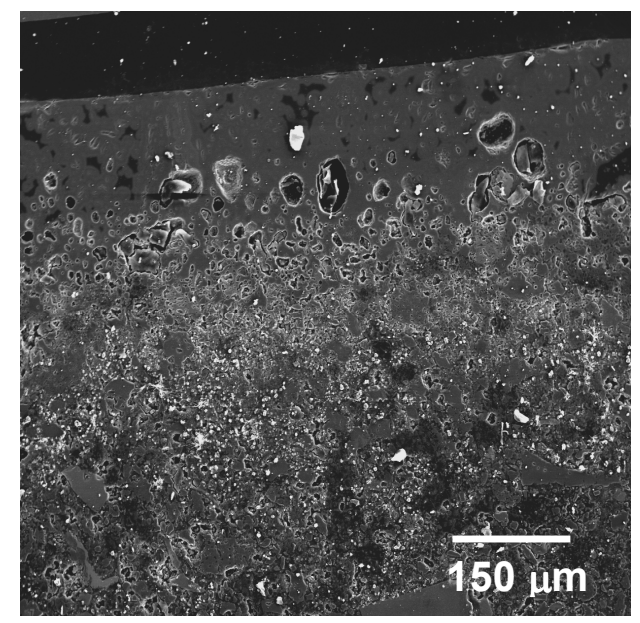


Fig. 4

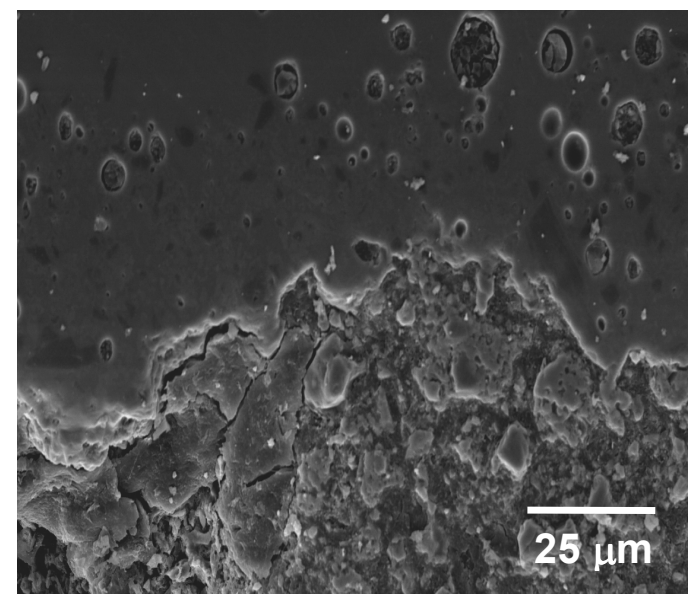


Fig. 5

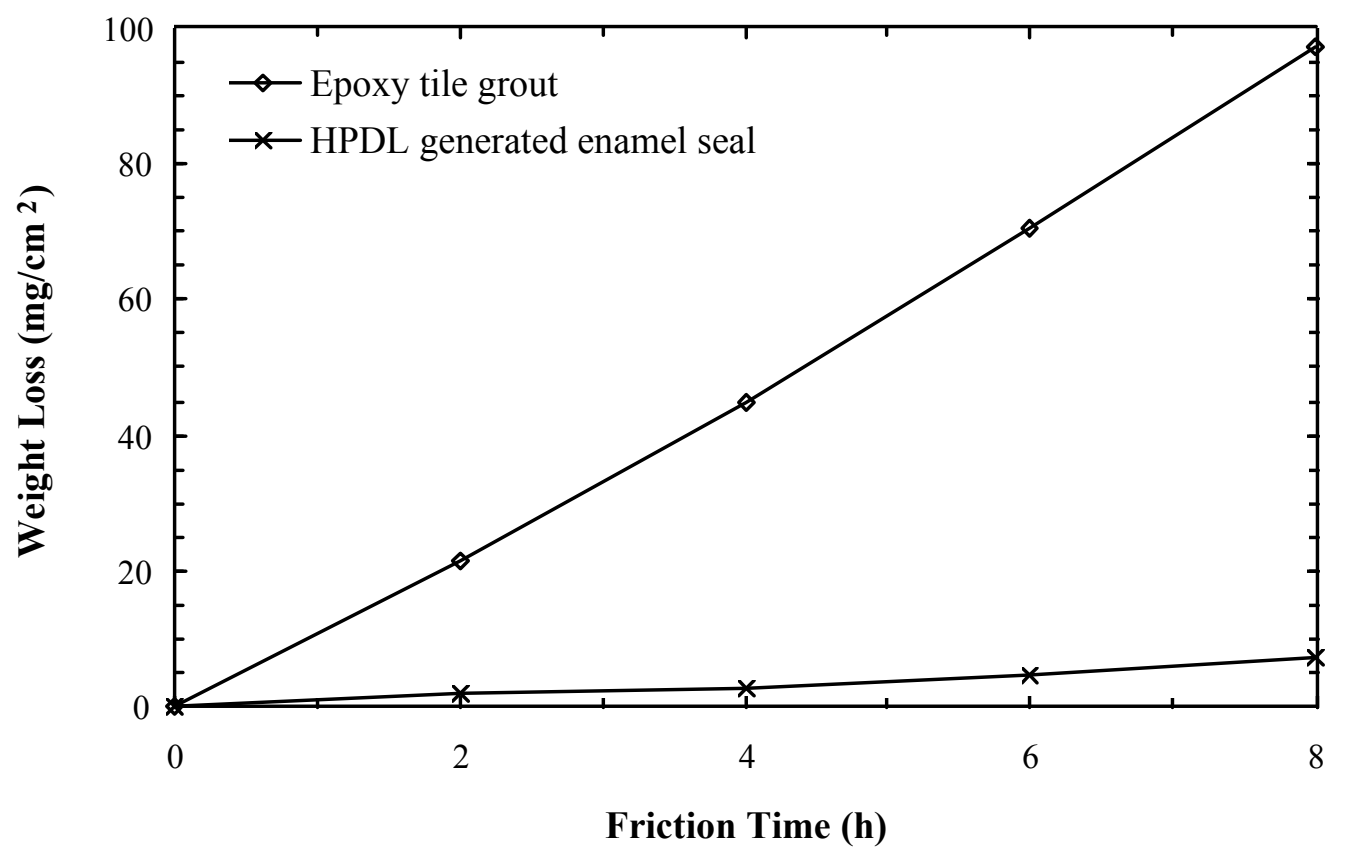


Fig. 6

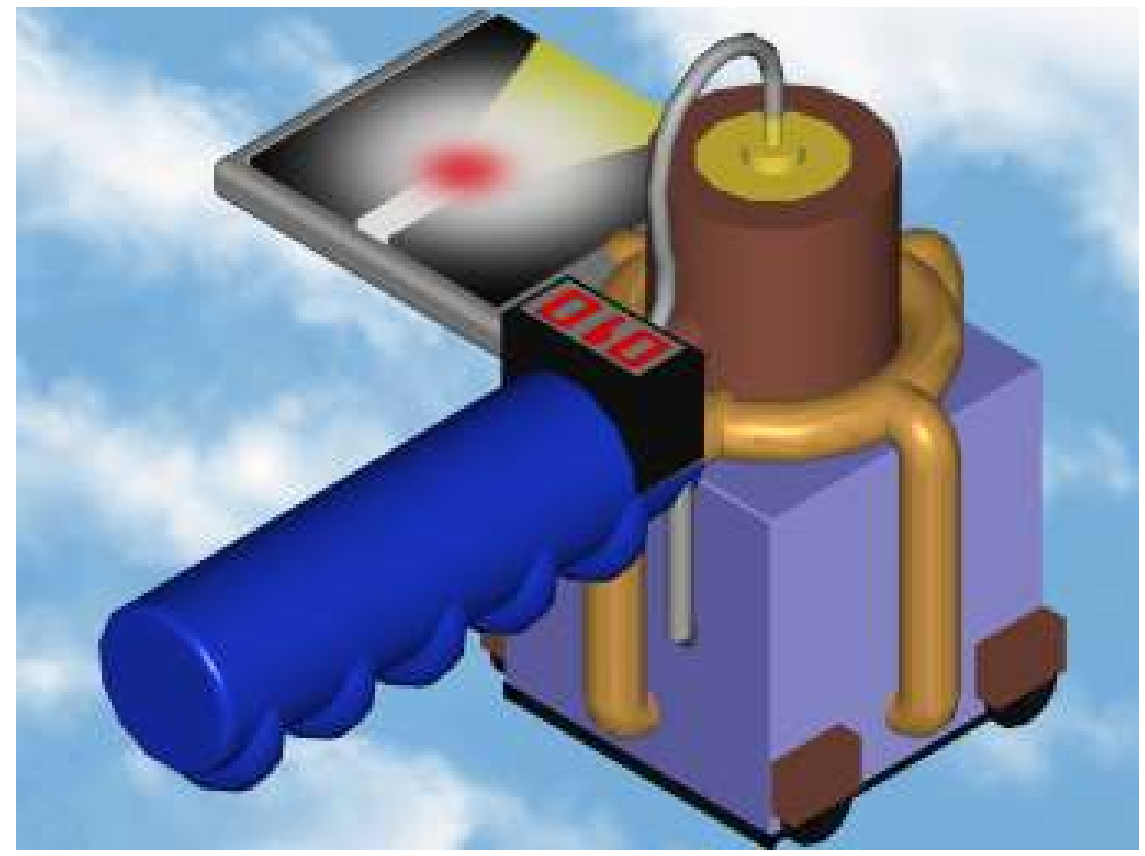




\section{List of Tables}

Table 1. Surface roughness (Ra) measurements for an epoxy tile grout, the vitrified surface of a ceramic tile and HPDL generated enamel glaze.

Table 2. Wear rate details and the nominal life increase of the HPDL generated enamel glaze over epoxy tile grout in various corrosive environments.

Table 3. MPE values for HPDL radiation for an exposure time of $10 \mathrm{~s}$. 
Table 1.

\begin{tabular}{lcc}
\hline \multicolumn{1}{c}{ Surface } & \multicolumn{2}{c}{ Surface Roughness (Ra) } \\
& Range & Ave. Roughness \\
\hline Epoxy tile grout & $2.36-5.72 \mu \mathrm{m}$ & $3.83 \mu \mathrm{m}$ \\
Vitrified ceramic tile & $0.06 \mu \mathrm{m}$ & $0.06 \mu \mathrm{m}$ \\
HPDL generated enamel glaze & $0.08-0.17 \mu \mathrm{m}$ & $0.12 \mu \mathrm{m}$ \\
\hline
\end{tabular}


Table 2.

\begin{tabular}{|c|c|c|c|c|c|c|}
\hline & \multirow[b]{2}{*}{ Density } & \multirow[b]{2}{*}{ Thickness } & \multicolumn{4}{|c|}{ Wear Rate $\left(\mathrm{mg} / \mathrm{cm}^{2} / \mathrm{h}\right)$} \\
\hline & & & Unexposed & Detergent & $\mathrm{NaOH}$ & $\mathrm{HNO}_{3}$ \\
\hline Epoxy tile grout & $2220\left(\mathrm{~kg} / \mathrm{m}^{3}\right)$ & $2000(\mu \mathrm{m})$ & 12.1 & 51.9 & 91.9 & 123.3 \\
\hline Enamel glaze & $2650\left(\mathrm{~kg} / \mathrm{m}^{3}\right)$ & $500(\mu \mathrm{m})$ & 0.9 & 0.9 & 0.9 & 0.9 \\
\hline \multicolumn{3}{|c|}{ Increase in Wear Life* } & 4.0 & 17.5 & 31.3 & 42.0 \\
\hline
\end{tabular}

$$
{ }^{*} \text { Increase in Wear Life }=\frac{\text { Enamel glaze wear life }}{\text { Epoxy tile grout wear life }}
$$

where,

$$
\text { Wear Life }=\frac{\text { Density } . \text { Thickness }\left(\mathrm{mg} \cdot \mathrm{cm} / \mathrm{cm}^{3}\right)}{\text { Wear Rate }\left(\mathrm{mg} / \mathrm{cm}^{2} / \mathrm{h}\right)}
$$


Table 3

\begin{tabular}{|c|c|c|c|c|c|c|c|c|c|}
\hline \multirow[t]{2}{*}{ Type of Exposure } & \multicolumn{3}{|c|}{$\begin{array}{c}\text { MPE Value } \\
\left(\mathrm{J} / \mathrm{m}^{2}\right)\end{array}$} & \multicolumn{3}{|c|}{$\begin{array}{l}\text { MPE Equivalent Fluence } \\
\qquad\left(\mathrm{J} / \mathrm{m}^{2}\right)\end{array}$} & \multicolumn{3}{|c|}{$\begin{array}{l}\text { MPE Equivalent Irradiance } \\
\left(\mathrm{W} / \mathrm{cm}^{2}\right)\end{array}$} \\
\hline & $10 \mathrm{~s}$ & $1 \mathrm{~s}$ & $10^{-3} \mathrm{~s}$ & $10 \mathrm{~s}$ & $1 \mathrm{~s}$ & $10^{-3} \mathrm{~s}$ & $10 \mathrm{~s}$ & $1 \mathrm{~s}$ & $10^{-3} \mathrm{~s}$ \\
\hline Ocular Exposure & 167.9 & 25.8 & 0.09 & 0.016 & 0.002 & $9 \times 10^{6}$ & 0.0016 & 0.002 & 0.009 \\
\hline Skin Exposure & 32451 & 18299 & 3295 & 3.245 & 1.824 & 0.324 & 0.324 & 1.824 & 324.5 \\
\hline
\end{tabular}

